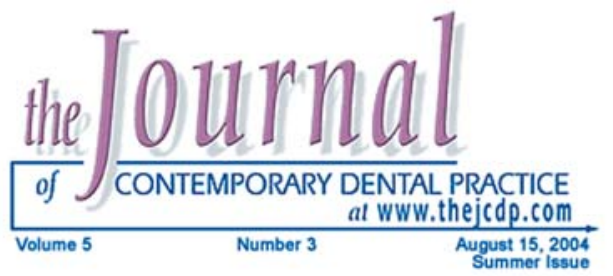

\title{
Partial Spontaneous Bone Regeneration Subsequent to Mandibulectomy
}

\section{Wilson Denis Martins, PhD; Lucia Fátima de Castro Ávila, DDS}

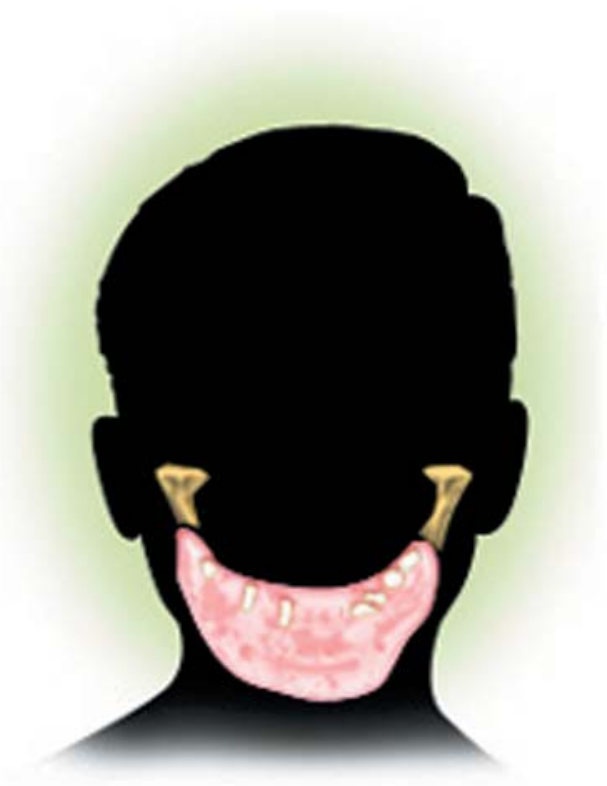

\section{Abstract}

A case of spontaneus bone regeneration after mandibulectomy is presented. The patient was young and had a mandibular resection performed for a large fibroma. Only one of the condyles was preserved. Partial preservation of the periosteum may play an important role in rapid bone regeneration. In this case bone regeneration occurred only in mandibular regions where the periosteum could be preserved.

Keywords: Mandibulectomy, spontaneous bone regeneration

Citation: Martins WD, Ávila LFC. Partial Spontaneous Bone Regeneration Subsequent to Mandibulectomy. J Contemp Dent Pract 2004 August;(5)3:108-120.

(C) Seer Publishing 


\section{Introduction}

Spontaneous bone regeneration after partial or total loss of the mandible has occasionally been reported in the literature. The reported causes of extensive bone loss were the results of a war injury ${ }^{1}$, an enucleation of large cysts ${ }^{2}$, infection $^{3}$, and a hemi or total mandibulectomy. ${ }^{4-16}$ Most of the reported cases occurred in children, adolescents, and young adults.

\section{Report of Case}

\section{Clinical Examination}

A 14-year old Caucasian boy was referred to the oral and maxillofacial surgeon because of an enlarging lesion of the mandible. Examination showed a large swelling of the anterior mandible (Figures 1 and 2). The health history revealed the swelling had been progressively enlarging since the boy was 10 years old. His family used to live in a remote rural Brazilian region with no available medical assistance. He had no previous treatment for his condition, and the family decided to seek assistance only when he was nearly unable to eat.

The patient was unable to fully close his mouth, and the surface of the mucosa was ulcerated (Figure 3). The anterior teeth were apparently absent, with the exception of two incisors displaced to the left side.

On palpation, the swelling was tender but bony hard. There were no palpable lymph nodes. The haemogram and blood chemistry were within the normal range.

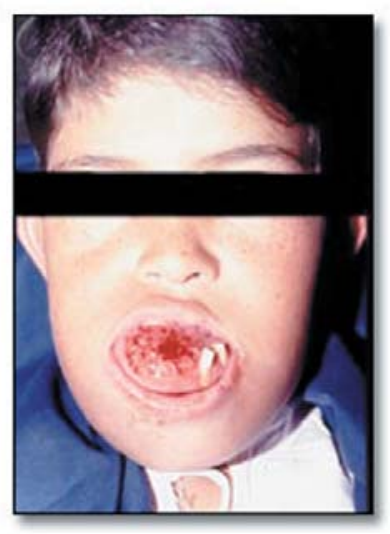

Figure 1. Frontal view.

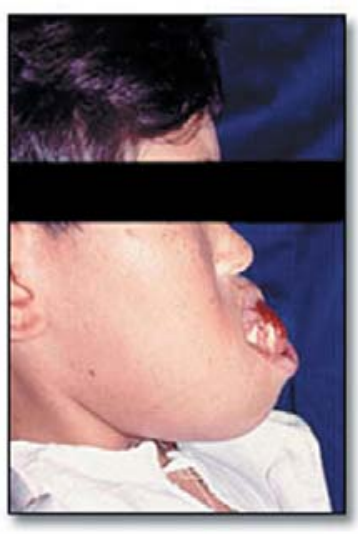

Figure 2. Lateral view.

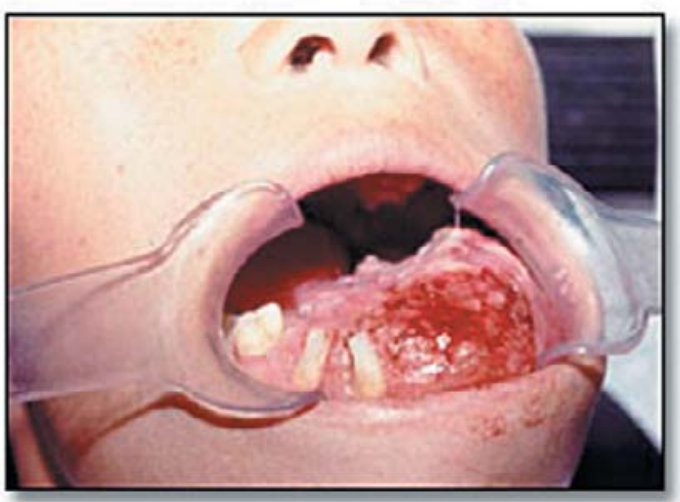

Figure 3. Ulcerated anterior mucosa.

\section{Radiographic Examination}

Radiographic examination showed a large multilocular, mixed radiopaque, and radiolucid area extending from the anterior region to the left and right mandibular bodies and ramus (Figures 4 and 5). The lower border of the mandible was very thin, and there were several teeth inside the tumoral mass.

\section{Incisional Biopsy}

Specimens from the lesion were obtained via an intraoral incisional biopsy under local anesthesia. Histologic examination revealed

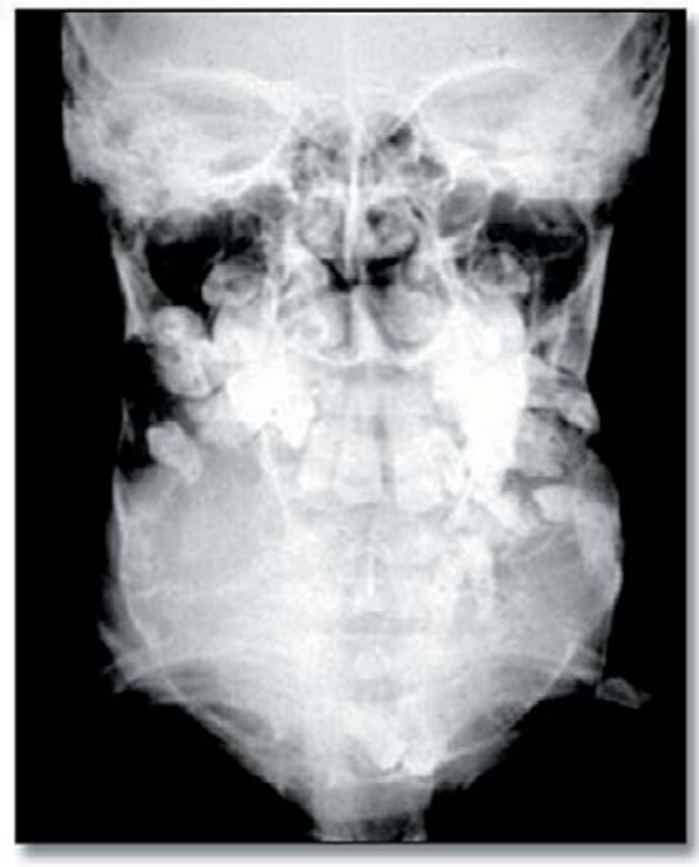

Figure 4. Posterior anterior radiograph. 


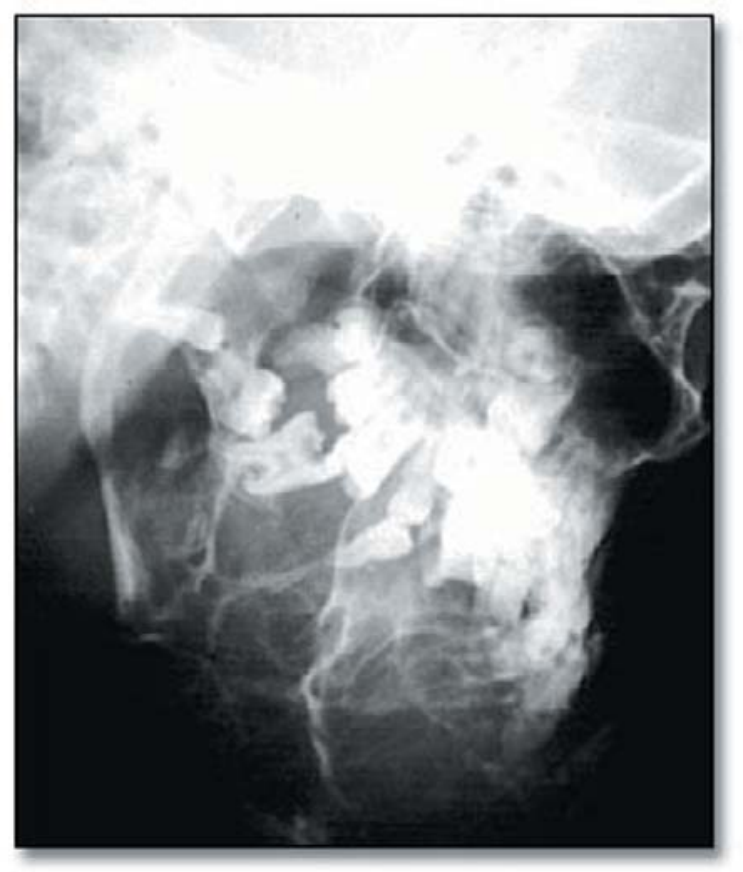

Figure 5. Lateral radiograph showing the multilocular pattern.

neoplasia with only a few fusiform cells with basophilic nuclei in a dense collagenous stroma. There was a presence of neoformed bone trabeculae with discrete osteoblastic activity (Figures 6 to 9). The diagnosis was ossifying fibroma.

\section{Surgical Procedure}

A tracheostomy was performed, and the patient was scheduled for surgery under general anesthesia. A submandibular incision from the left to the right mandibular angles was performed. The tumor was resected with difficulty in the anterior region since there was strong adhesion between the tumor, oral mucosa, and periosteum.

The periosteum was more easily detached by blunt dissection from the molar regions to the angle, and the periosteum of the ramus was preserved. The entire mandible was disarticulated, with the exception of the right condyle, coronoid process, and part of the ramus that appeared to be free from the neoplasia. Because of the unfavorable local conditions it was decided not to carry out simultaneous bone grafting, nor a placement of any kind of space contention device. The wound was closed in layers (Figure 10).

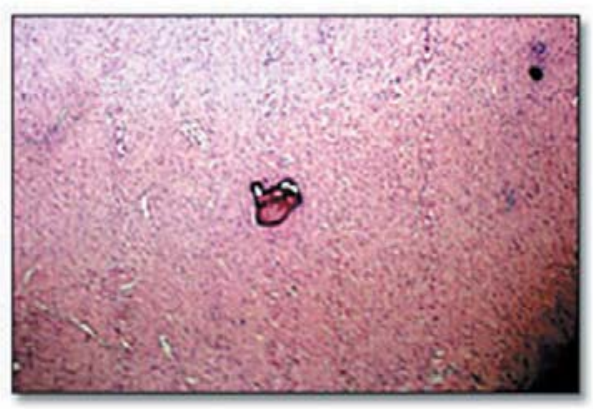

Figure 6. HE stain at $100 \times$ Fusiform cells with basophilic nuclei in a dense collagenous stroma.

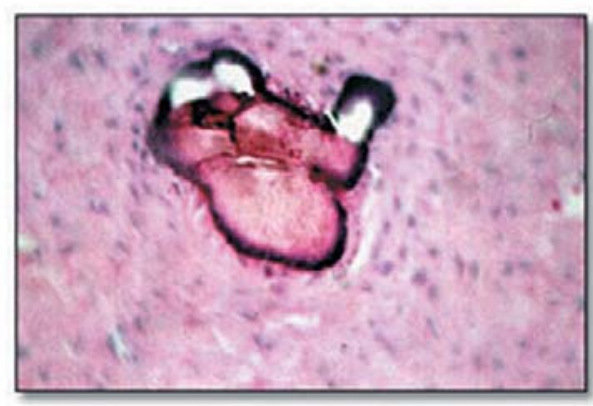

Figure 7. HE stain at $400 \times \mathrm{A}$ neoformed bone trabeculae.

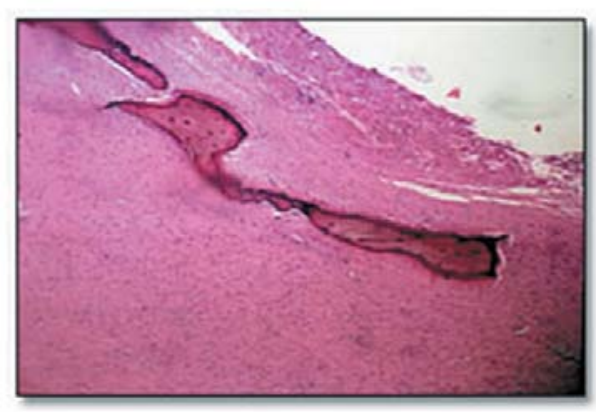

Figure 8. HE stain at $100 \mathrm{X}$ Fusiform cells with basophilic nuclei in a dense collagenous stroma. Presence of neoformed bone.

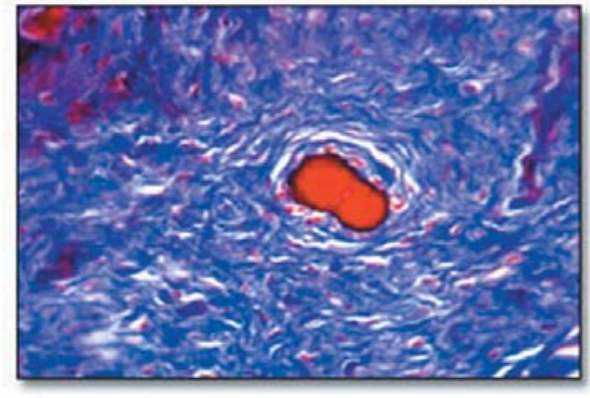

Figure 9. Mallory stain at $400 \mathrm{X}$ showing the fusiform cells are clearly evident. 


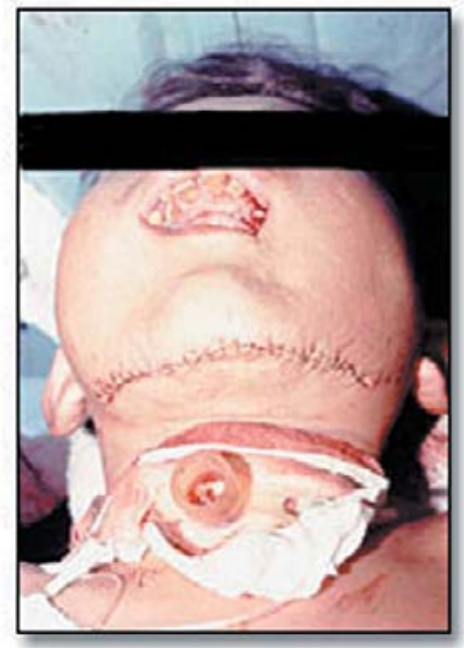

Figure 10. Aspect of the incision and sutures.

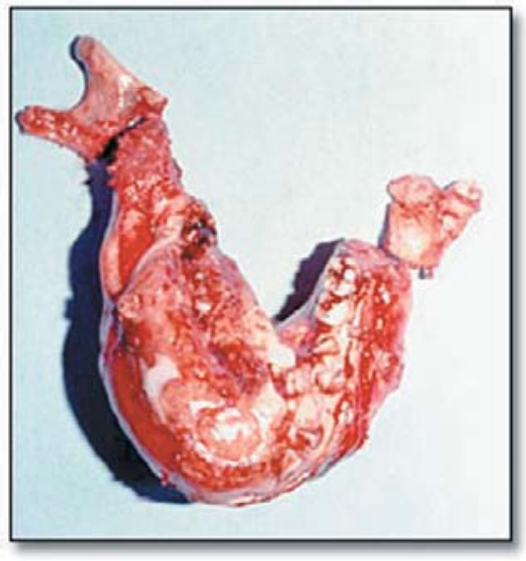

Figure 11. Resected mandible (superior view).

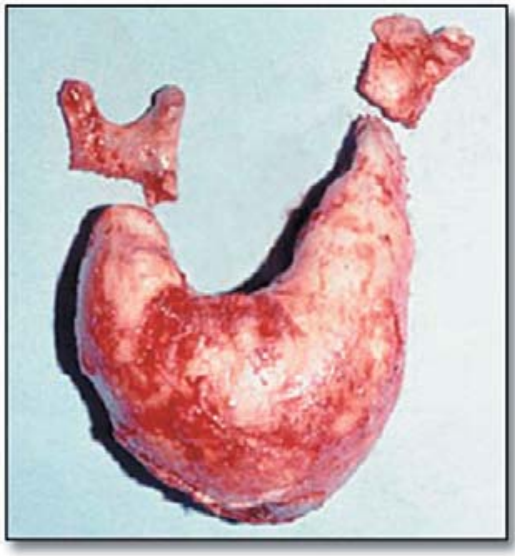

Figure 12. Resected mandible (inferior view).
The exarticulated mandible is shown in Figure 11 (occlusal view). The removed left condyle, coronoid process, and an isolated bony fragment of the right side containing a bicuspid tooth and part of the ramus are shown in Figure 12 (inferior view).

\section{Postoperative Course}

The postoperative course was uneventful, and the patient was able to eat soft food normally. The patient was discharged to be followed as an outpatient and was to return in 3 months for a bone graft. (Figures 13 and 14). Further histologic examination of the specimen confirmed the diagnosis of ossifying fibroma. The margins of the right condylar stump were free from neoplastic tissue.

The patient returned for a review only after two years. Surprisingly he presented an acceptable facial balance with minimal deformity. Some hard bony tissue was palpated intraorally, apparently replacing the resected mandible (Figure 15).

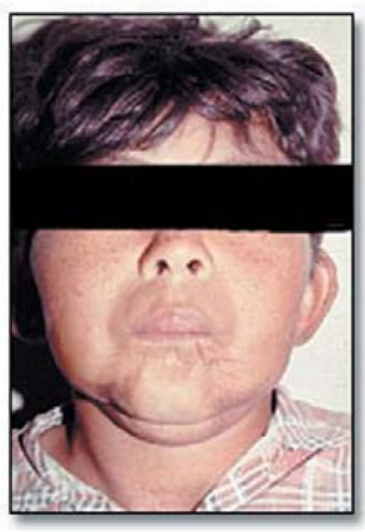

Figure 13. Frontal view 30 days following surgery.

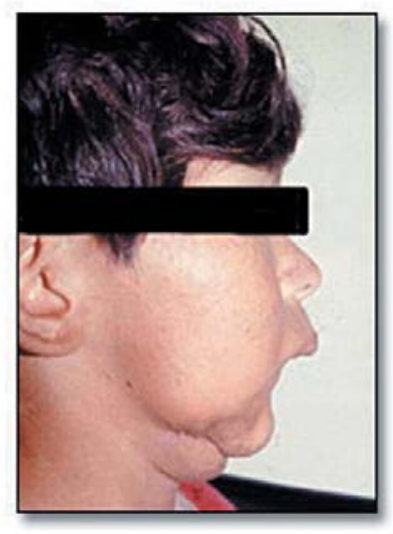

Figure 14. Lateral view 30 days following surgery.

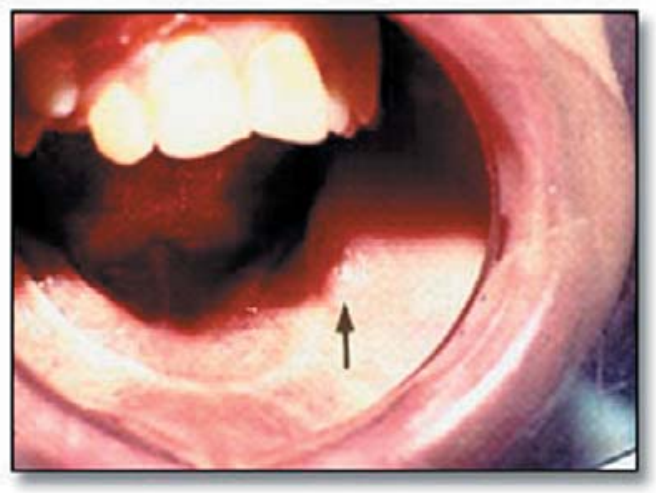

Figure 15. Site of the bone tissue (arrow). 


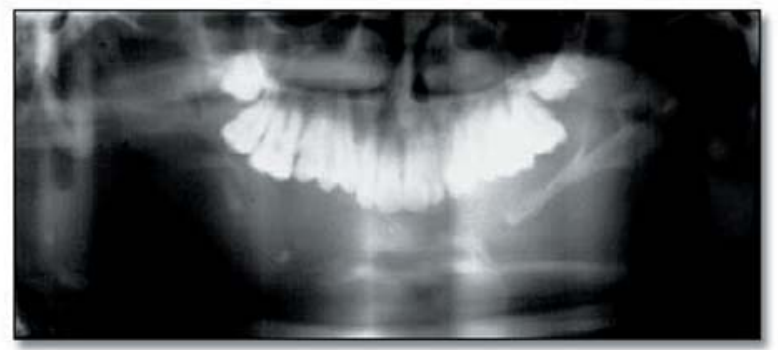

Figure 16. Radiopaque structure growing distally in the left side. Panoramic image.

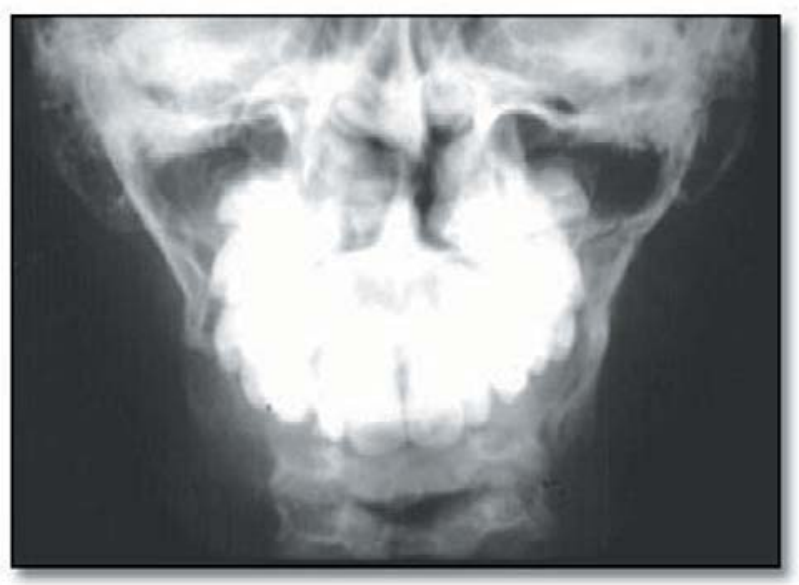

Figure 17. Postero-anterior image. The growing radiopaque structure is seen in the left side.

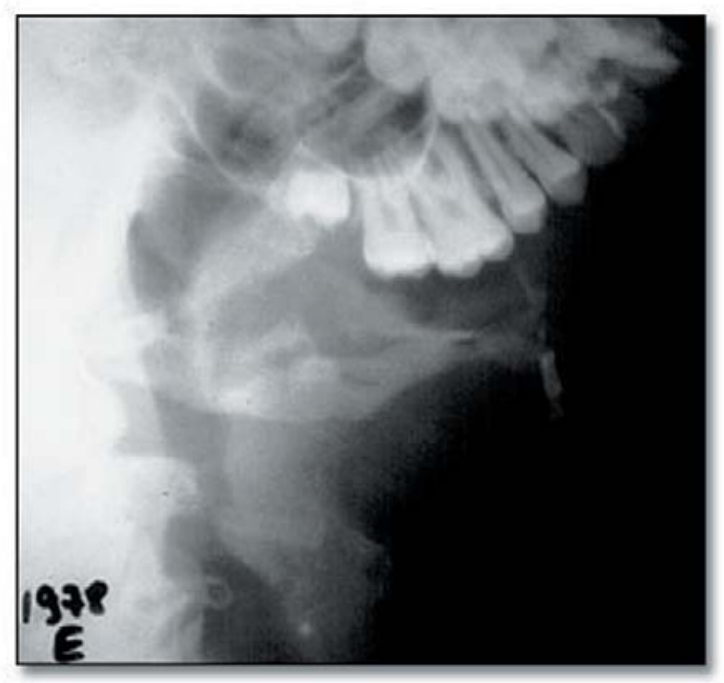

Figure 18. Left lateral of the mandible image. The new bone formation is clearly seen.
Postoperative Radiographic Re-evaluation Radiographic examination showed a radiopaque structure apparently growing distally in the left side. In the right side a smaller amount of hard tissue was observed, corresponding only to the remaining condyle, coronoid process, and part of the ramus that were preserved (Figures 16 to 18).

\section{Postoperative Histological Re-evaluation} An incisional biopsy was performed and a small fragment of the hard structure felt in the left side was removed. Histologic examination revealed normal bone structure with no signs of recurrence of the fibroma (Figures 19 and 20). The patient was discharged and a new appointment was planned in two years.

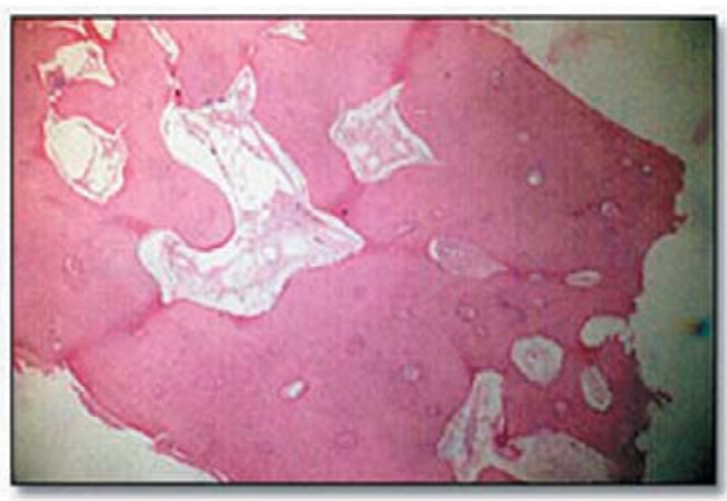

Figure 19. HE stain at 110X. Normal bone structure.

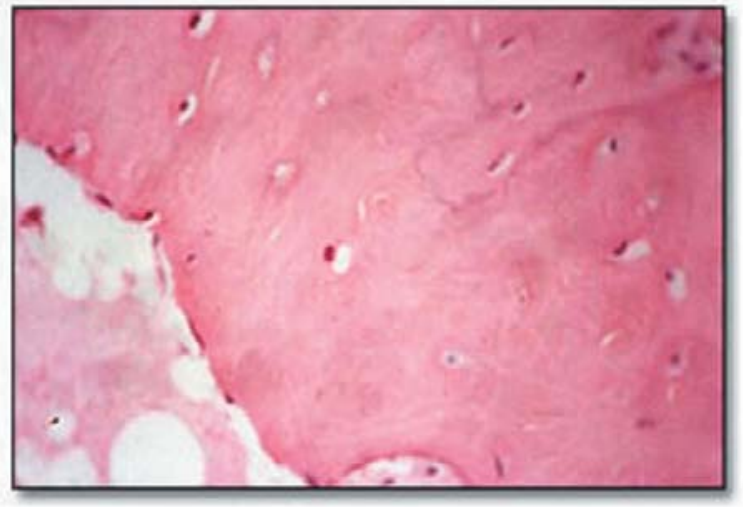

Figure 20. H stain at 400X. Normal bone structure. 


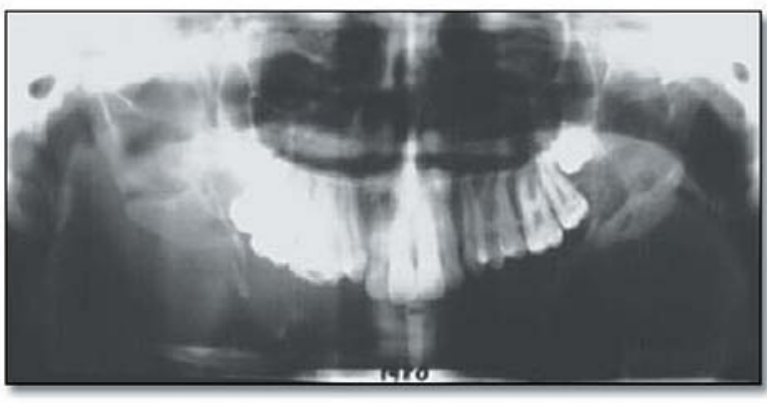

Figure 21. The amount of bone in the left side is the same. An increment in the bone density in the right angle can be observed.

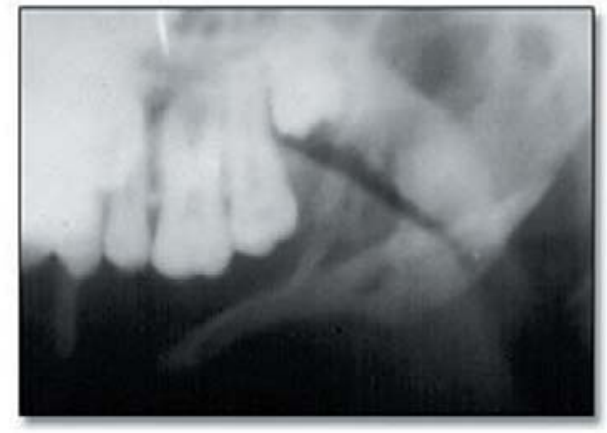

Figure 22. Right side image after 4 years.

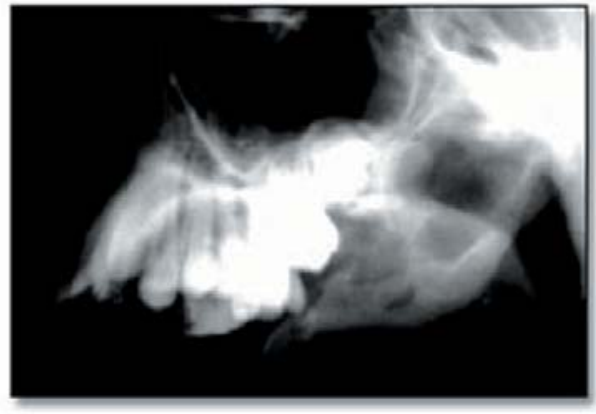

Figure 23. Left side image after 4 years.

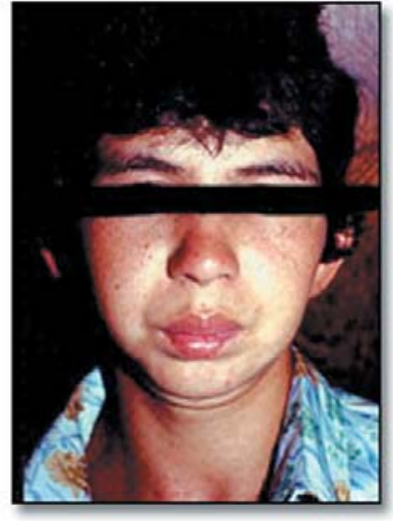

Figure 24. Frontal view of the patient after 4 years.

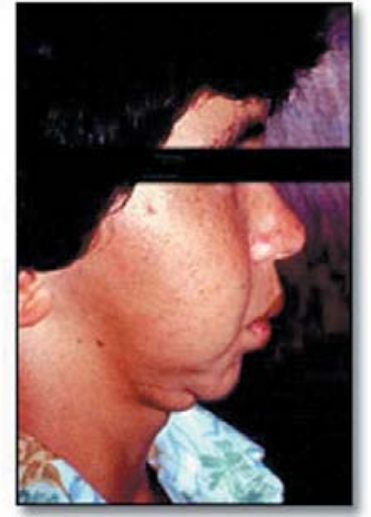

Figure 25. Lateral view of the patient after 4 years.

\section{Two-Year Follow-Up}

The patient returned for examination as scheduled. No marked differences in the intraoral aspect of the hard tissue previously felt on palpation were observed. Radiographic examination showed the same amount of bone in the left side and an increment in the bone density in the region corresponding to the angle in the right side. (Figures 21 to 23). The patient was perfectly adapted to the situation, and the family refused any further surgical or prosthetic treatment.

It was evident the patient's facial development was consistent with his age (Figures 24 and 25).

\section{Discussion}

In most similar cases in the literature in which grafts were not used, the spontaneus bone regeneration was credited to the maintenance of the periosteum..$^{10,8,17,5,18,11}$ However, the function of the periosteum and other sources of osteogenesis are somewhat controversial. ${ }^{1,19}$ When the periosteum is stripped from the bone, it would carry with it only some of the osteogenic cells and the bone is by no means deprived of its osteogenic potential. ${ }^{1}$

\section{Conclusion}

In the present case, the periosteum was maintained in the molar region and proximally to the ramus and condylar regions. The pattern of the bone regeneration followed the periosteal "bed," mainly in the left side, where the bone formation was more evident. 


\section{References}

1. Shuker S. Spontaneous regeneration of the mandible in a child. A sequel to partial avulsion as a result of a war injury. J Maxillofac Surg. 1985 Apr;13(2):70-3.

2. Chiapasco M, Rossi A, Motta JJ, et. al. Spontaneous bone regeneration after enucleation of large mandibular cysts: a radiographic computed analysis of 27 consecutive cases. J Oral Maxillofac Surg. 2000 Sep;58(9):942-8; discussion 949.

3. Elbeshir E. Spontaneous regeneration of the mandibular bone following hemimandibulectomy. $\mathrm{Br} \mathrm{J}$ Oral Maxillofac Surg. 1990 Apr;28(2):128-30. Review.

4. Szlazak JP. Clinical observation of the spontaneous regeneration of the mandible. Acta Chir Plast. 1966;8(3):201-4. No abstract available.

5. Ruggiero SL, Donnof RB. Bone regeneration after mandibular resection: report of two cases. J Oral Maxillofac Surg. 1991 Jun;49(6):647-52. No abstract available.

6. Whitmyer CC, Esposito SJ, Smith JD, et. al. Spontaneous regeneration of a resected mandible in a preadolescent: a clinical report. J Prosthet Dent. 1996 Apr;75(4):356-9. No abstract available.

7. Anastassov K, Popov K. [Complete regeneration of the body of the ascending ramus and mandibular condyle in a child after disarticulation] Rev Odontostomatol (Paris). 1975 Jan-Feb;4(1):43-50. French. No abstract available.

8. Boyne PJ. The restoration of resected mandibles in children without the use of bone grafts. Head Neck Surg. 1983 Nov-Dec;6(2):626-31.

9. Nwoku AL Unusually rapid bone regeneration following mandibular resection. J Maxillofac Surg. 1980 Nov;8(4):309-15.

10. Budal J. The osteogenic capacity of the periosteum. Oral Surg Oral Med Oral Pathol. 1979 Mar;47(3):227-9. No abstract available.

11. Adekeye EO. Rapid bone regeneration subsequent to subtotal mandibulectomy. Report of an unusual case. Oral Surg Oral Med Oral Pathol. 1977 Oct;44(4):521-6.

12. Francksen U. Periostale regeneration des unterkiefers nach halbseitiger exartikulation. Fortschr Kiefer-Gesichtschir 1958;4:337.

13. Haunfelder D. [On regeneration of the mandible after subperiosteal resection and exarticulation] Chirurg. 1962 Feb;33:62-6. German. No abstract available.

14. Kazanjian, V. Spontaneous regeneration of bone following excision of section of the mandible. Oral Surg 1948; 32:242.

15. Nagura H. [Bone regeneration following mandibular resection] Kokubyo Gakkai Zasshi. 1979 Mar;46(1):106. Japanese. No abstract available.

16. Nishijima K. Bone regeneration after hemimandibulectomy including mandibular condyle. Jpn J Oral Surg 1975; 21: 491

17. McClements P, Templeton RW, Pritchard JJ. Repair of a bone gap. J Anat 1961; 95:616.

18. Nagase M, Ueda K, Suzuki I, et. al. Spontaneous regeneration of the condyle following hemimandibulectomy by disarticulation. J Oral Maxillofac Surg. 1985 Mar;43(3):218-20. No abstract available.

19. McEwan W. The growth of bone. McLehose, Glasgow 1912. 
About the Authors

\section{Wilson Denis Martins, PhD}

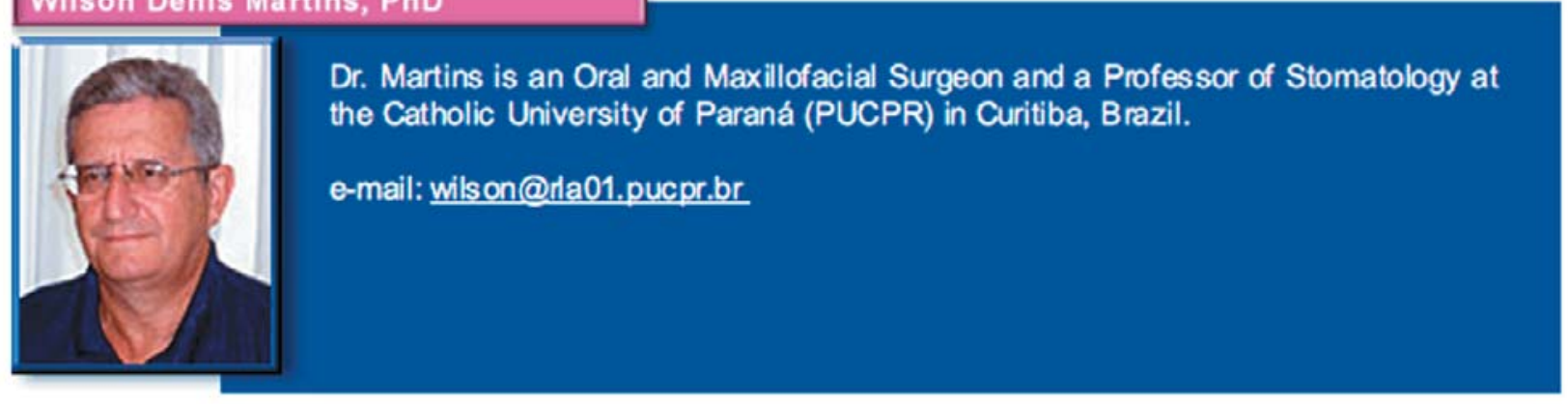

Lucia Fátima de Castro Ávila, DDS

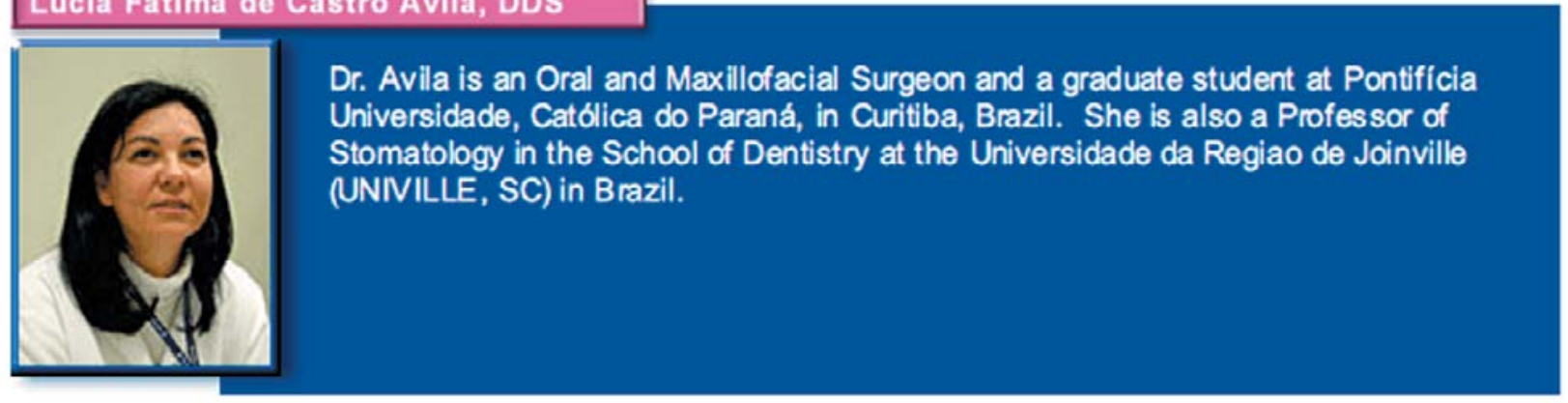

